\title{
COMPARISON OF SHORT-TERM AND LONG-TERM OUTCOMES OF LAPAROSCOPY VERSUS LAPAROTOMY IN RECTAL CANCER: SYSTEMATIC REVIEW AND META-ANALYSIS OF RANDOMIZED CONTROLLED TRIALS.
}

Lina Boualila, Amine Souadka, Zaineb Benslimane, Laila Amrani, Amine Benkabbou, Mohsine Raouf, Mohamed Anass Majbar National Institute of Oncology, CHU Ibn Sina, University Mohamed V ${ }^{\text {th }}$, Rabat, Morocco

\section{ABSTRACT}

Background and objective: The last randomized controlled trials the ACOSOG Z6051, and the ALaCaRT trial could not show the non-inferiority of the laparoscopy in comparison to laparotomy for rectal cancer. In fact, the ten first years of practicing laparoscopy were years when surgeons developed their learning curve. Therefore, by excluding this learning bias, it is possible to end up with a more fair and correct comparison between the two techniques. It is henceforth relevant to pursue a new meta-analysis that compares the two techniques and excludes studies done during the earlier periods of laparoscopic rectal surgery. Results: Six randomized controlled trials met the eligibility criteria, involving a total of 1556 patients in the laparoscopy group and 1188 patients in the laparotomy group. Our meta-analysis was in favor of laparoscopy in a significant way for blood loss, first bowel movement and the number of harvested lymph nodes. It was non-significantly in favour of laparoscopy for 30-days mortality after surgery and length of hospital stay. It was significantly in favor of laparotomy for operative duration. No significant difference was found in anastomotic leakage), reoperation within 30 days, number of positive CRMs and completeness of mesorectal excision between the two groups. No difference was found in recurrence, disease-free survival and overall survival between laparoscopy group and laparotomy group. Conclusion: The comparison of the randomized controlled trials published before and after 2010, showed no significant difference in outcomes between the learning period and after.

Keywords: Laparoscopy, laparotomy, long-term outcomes, meta-analysis, rectal cancer, short-term outcomes

Corresponding Author:

Lina Boualila, MD.

Address: National institute of oncology, Ibn Sina University Hospital, University Mohamed V, Rabat, Morocco.

ORCID ID: https://orcid.org/0000-0003-3948-9782

E-mail: 1.boualila@um5s.net.ma

Copyright (c) 2012- 2021 L. Boualila et al. This is an open access article published under Creative Commons Attribution -Non Commercial- No Derives 4.0 International Public License (CC BY-NC-ND). This license allows others to download the articles and share them with others as long as they credit you, but they can't change them in any way or use them commercially. $* * * * *$ Published in 2021.

doi: 10.46327/msrjg.1.000000000000197

doi url: https://doi.org/10.46327/msrjg.1.000000000000197

\section{INTRODUCTION}

Surgery constitutes the mainstay of rectal cancer treatment. The use of laparoscopy in colorectal pathology has been widely adopted. It has been demonstrated that laparoscopy had better postoperative outcomes and similar oncological outcomes than laparotomy in colon cancer [1]. In the late 90's, laparoscopy had 3 basic roles in colorectal cancer: diagnosis especially staging, palliative management of patients with incurable colorectal cancer and an unproved role in the treatment of curable cancer [2]. In 2005, the Standard Practice Task Force of ASCRS announced that: "Laparoscopic techniques for rectal cancer are established and feasible, meanwhile for colon cancer is safe and effective" [3, 4]. (Class II Level of Evidence and Degree of Recommendation B).
Among the first trials that compared short-term and long-term outcomes of laparoscopy and laparotomy in colorectal cancer, the MRC (Medical Research Council) CLASICC controlled trial [5] reported a similar longitudinal resection margins and lymph-node yield in both groups, a non-significant higher rate of tumorpositive circumferential resection margins after laparoscopic surgery. No significant difference was found in local recurrences rate or 3-years overall survival [OS], disease-free survival [DFS], and quality of life [6]. The authors concluded that tumor-positive circumferential resection margins rate was higher after laparoscopic surgery, as a main conclusion of the study, despite the non-significance of the result [7]. The last randomized controlled trials, the ACOSOG Z6051 [8, 9] in 2015-2019 and the ALaCaRT trial $[10,11]$ in 20152019 could not show the non-inferiority of the 
laparoscopy in comparison to laparotomy in rectal cancer. In fact, the ten first years of practicing laparoscopy were years when surgeons developed their learning curve and could acquire the needed expertise only after 2010. Therefore, by excluding this learning bias, it is possible to end up with a more fair and correct comparison between the two techniques. It is henceforth relevant to pursue a new meta-analysis that compares the two techniques and excludes studies done during the earlier periods of laparoscopic rectal surgery.

\section{METHODS}

This systematic review and meta-analysis was performed in accordance with the Preferred Reporting Items for Systematic Review and Meta-Analyses (PRISMA) statement and following the Meta-Analysis and systematic review Cochrane guidelines [12].

\section{Eligibility criteria}

We aimed at identifying all randomized controlled trials that compared short term outcomes and long term outcomes post laparoscopy and laparotomy in patients with rectal cancer.

The inclusion criteria were:

-Randomized controlled trials

-Papers published after 2010.

-Primary Rectal adenocarcinoma.

-Comparison of laparoscopy and laparotomy

-Patients over 18 years old.

The exclusion criteria were the following:

-Duplicate or repeat studies

-Meta-analysis, non-comparative studies, conference abstracts, expert opinions, editorials, letters and commentaries.

-Non-human research.

-Interventions on cadavers.

-Articles with languages other than French or English.

-Studies with benign lesions.

-Robotic surgery and transanal mesorectal excisions.

-Single-port laparoscopic surgery.

\section{Literature search strategy}

A search was performed in the PubMed database and Cochrane library on 12th November 2019. We identified the Medical Subject Headings (MeSH) terms for rectal cancer which is "rectal neoplasm", and for laparoscopy which is "laparoscopy ", then launched the research by combining the two items. The following key words and Medical Subject Headings (MeSH) terms were used for both databases:

MESH: rectal neoplasms/Rectal cancer (Title or abstract)/ Cancer AND rectum (Title or abstract)/ Cancer AND rectal (Title or abstract)/ Tumor AND rectum (Title or abstract)/ Tumor AND rectal (Title or abstract)/ Tumour AND rectum (Title or abstract)/ Tumour AND rectal (Title or abstract)/ Adenocarcinoma AND rectum (Title or abstract)/ Adenocarcinoma AND rectal (Title or abstract)/ Rectal resection (Title or abstract), Proctectomy (Title or abstract)/ Anterior resection (Title or abstract), Low anterior resection (Title or abstract)/ Mesorectal excision (Title or abstract)/ Abdominoperineal resection (Title or abstract)/ Abdomino-perineal resection (Title or abstract)/

MeSH: Laparoscopy/Mini-invasive surgery (Title or abstract)/ Mini-invasive surgery (Title or abstract)/Laparoscopic (Title or abstract).

\section{Study selection}

Study selection was performed in three phases according to the PRISMA statement (Figure 1). After identifying the articles, using the first filter which comprises of the inclusion and exclusion criteria, two independent researchers selected articles based on the titles and abstracts. All discrepancies were resolved by discussion and consensus. The same researchers screened full texts and selected studies for inclusion in the systematic review and the meta- analysis. Discrepancies at this stage were resolved by discussion and consensus. Six trials met the eligibility criteria. Papers from the same trial were analyzed as one study. Four trials presented two papers for short-term and long-term outcomes, and two presented all outcomes in one paper. Table I represents the selected studies in column, year of publication, Digital Object Identifier of papers studying short-term and long-term outcomes and country in line. Table II represents baseline characteristics of the studied population in each trial. 

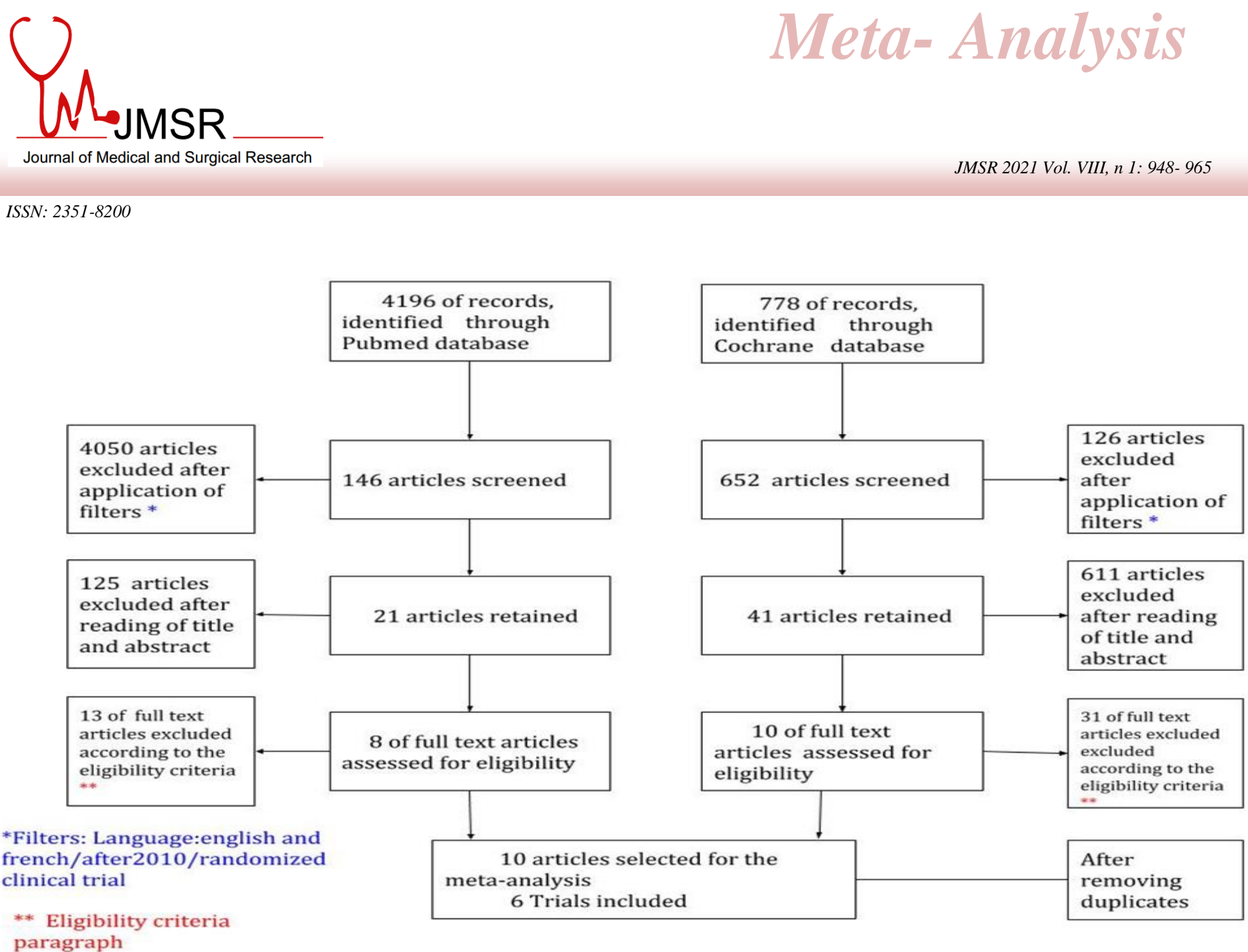

Figure 1: PRISMA diagram

Table I: Selected randomized controlled trials in this meta-analysis.

\begin{tabular}{ccccc}
\hline Trial & Year of publication & Short-term outcomes & Long-term outcomes & Country \\
\hline COLOR II & 2013 & Pas et al [13] & Bonjer et al [14] & Multi-center \\
& 2015 & & & Australia \\
ALaCaRT & 2015 & Stevenson et al [10] & Stevenson et al [11] & Korea \\
COREAN trial & 2019 & Kang et al [15] & Jeong et al [16] & USA \\
ACOSOG Z6051 & 2014 & & Fleshman et al [8] & Hong Kong \\
Ng's trial & 2015 & Fleshman et al [9] & Ng et al [17] & Liang et al [18] \\
Liang' s trial & 2014 & Liang et al [18] & & China
\end{tabular}




\section{Outcome Measures}

\section{*Short term outcomes}

For per- operative outcomes, this meta-analysis compared: Blood loss (mL).

Operative duration (min).

For the post-operative outcomes, it included:

Length of hospital stay (days).

Reoperation (Within 30 days from surgery).

First bowel movement (days).

Anastomotic leakage.

Mortality (from the day of surgery until 30 days

after).

Regarding the histology of the specimen, the primary outcomes were:

- $\quad$ Number of harvested lymph nodes.

- CRM status (Circumferential Radial Margin).

- Completeness of mesorectal excision.

On the basis of Nagtegaal et al. classification [20], and in order to make a meta-analysis, we grouped "complete" and "nearly complete" mesorectal excisions as "complete" and were compared with "incomplete" mesorectal excisions.

\section{*Long term outcomes}

The primary outcomes were loco regional recurrence, overall survival and disease free-survival.

\section{Statistical Analysis}

Analysis was performed using RevMan 5.3 (freeware from the Cochrane Collaboration) Review Manager Web (RevMan Web). The Cochrane Collaboration, 2019. Available at revman.cochrane.org. We used mean and standard deviation when it was provided by the study. According to the Cochrane handbook, the median is very similar to the mean when the distribution of the data is symmetrical, and so occasionally can be used directly in meta-analyses. In addition to that, the width of the interquartile range will be approximately 1.35 standard deviations [21]. We started from this principle to obtain mean and standard deviation when non-provided, in order to do a meta-analysis. For the dichotomous data, the statistical method used is the Odds ratios, by means of the MantelHaenszel fixed-effects with pertinent $95 \%$ confidence intervals (CI). Concerning the continuous data, the statistical method used was the mean difference by the mean of the inverse variance fixed-effect method with pertinent $95 \%$ confidence intervals (CI). Results were presented in forest plots, providing estimate of the mean proportion with a $95 \%$ confidence interval (CI) [22].

\section{RESULTS}

\section{Search strategy}

A total of 4196 records were identified through PubMed database search and 778 records through Cochrane database search (Figure 1). After applying the research filters which are: randomized controlled trials, articles written in English or French and published after 2010; 146 records were retained from the PubMed database and 652 records from the Cochrane database. When screening titles, abstracts and full articles, we retained 8 articles and 10 articles from PubMed database and Cochrane databases respectively. After removing duplicates, 10 articles were screened for eligibility according to the eligibility criteria previously cited. Papers from the same trial were analyzed as one study, so that a total of 6 trials were analyzed : COLOR II $[13,14]$, AlaCart [10,11] ,COREAN trial [15,16] , ACOSOG Z6051[8,9], Ng's trial[17] and Liang's trial[18]. There were 4 trials( COLOR II[13,14], AlaCart [10,11] ,COREAN trial $[15,16]$, ACOSOG Z6051[8,9]) in which results were reported in two papers, one paper reporting short term outcomes and the other long term outcomes. Ng's trial[17] and Liang's trial[18] presented both short and long term outcomes in the same paper. A total of 1556 patients in the laparoscopic group and 1188 patients in the open group were analyzed in the present meta-analysis (Figure 1).

\section{Short term outcomes}

\section{Per operative outcomes}

\section{Operative duration}

Operative duration was reported in all trials. In COLOR II trial $[13,14]$ and AlaCart trial $[10,11]$, results were reported in median and range, therefore, the means and standard deviation were calculated as stated in the statistical analysis section .The analysis showed that operative duration was significantly shorter in the laparotomy group with a mean difference of 28.51 minutes [24.74, 32.28] CI $95 \%$ $(\mathrm{p}<0.00001)$ (Figure 3).

\section{Blood loss}

Blood loss (mL) was analyzed in five trials, out of 1387 patients in the laparoscopy group and 1012 in the laparotomy group. Results were given in median and range in the : COLOR II trial[13,14], AlaCart trial[10,11] ,COREAN trial $[15,16]$ and Ng's trial[17]. . Therefore, the means and standard deviations were calculated as stated in the statistical analysis section. The findings showed that blood loss was statistically lower in the laparoscopy group: Mean difference $-70.62 \mathrm{ml}[-88.84,-52.40]$ CI $95 \%$ $(\mathrm{p}<0.00001)$ (Figure 4). 


\begin{tabular}{|c|c|c|c|c|c|c|c|c|c|c|c|c|}
\hline \multirow{2}{*}{ Study or Subgroup } & \multicolumn{3}{|c|}{ Laparoscopy } & \multicolumn{3}{|c|}{ Laparotomie } & \multicolumn{3}{|c|}{ Mean Difference } & \multirow{2}{*}{\multicolumn{2}{|c|}{$\begin{array}{l}\text { Mean Difference } \\
\text { N, Fixed, } 95 \% \mathrm{Cl} \text { [Min] }\end{array}$}} & \\
\hline & Diean [Mini] & $\mathrm{SD}$ [Min] & Iotal & Mean [Min] & SD [Bin] & Iotal & Weight & IV, fDea, 95\% CI [min] & Year & & & \\
\hline Kang 2010 & 244.9 & 75.4 & 170 & 197 & 62.9 & 170 & $6.5 \%$ & $47.90[33.14,62.66]$ & 2010 & & $\longrightarrow$ & \\
\hline Llang 2011 & 138.08 & 23.76 & 169 & 118.53 & 21.98 & 174 & $60.5 \%$ & $19.55[14.70,24.40]$ & 2011 & & 口 & \\
\hline vanderpas 2013 & 240 & 85.92 & 699 & 188 & 73.33 & 345 & $14.2 \%$ & $52.00[41.98,62.02]$ & 2013 & & $\rightarrow$ & \\
\hline $\mathrm{ng} 2014$ & 211.6 & 53 & 40 & 153 & 41.1 & 40 & $3.3 \%$ & $58.60[37.82,79.38]$ & 2014 & & & \\
\hline Stevenson 2015 & 210 & 66.66 & 238 & 190 & 59.25 & 235 & $11.0 \%$ & $20.00[8.64,31.36]$ & 2015 & & - & \\
\hline Fleshman 2015 & 266.2 & 101,9 & 240 & 220.6 & 92.4 & 222 & $4.5 \%$ & $45.60[27.88,63.32]$ & 2015 & & & \\
\hline Total $(95 \% \mathrm{Cl})$ & & & 1556 & & & 1186 & $100.0 \mathrm{~s}$ & $28.51[24.74,32.28]$ & & & $\bullet$ & \\
\hline \multicolumn{10}{|c|}{$\begin{array}{l}\text { Heterogeneity, } C h i^{2}=54.64, d f=5(P<0.00001) ; P=91 \% \\
\text { Test for overall effect: } Z=14.82(P<0.00001)\end{array}$} & $\begin{array}{cc}-100 & -50 \\
\text { Favours ILaparos }\end{array}$ & $\begin{array}{ll}0 & 50 \\
\text { Favours ILa }\end{array}$ & $\begin{array}{c}100 \\
\text { otomy] }\end{array}$ \\
\hline
\end{tabular}

Figure 3 : Pooled estimates of operative duration comparing laparoscopy to laparotomy. CI confidence interval, df degrees of freedom

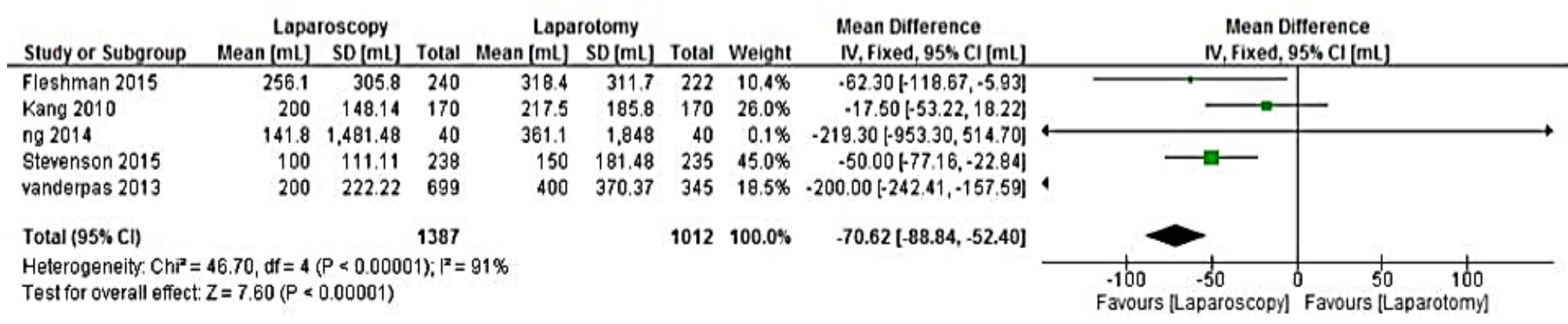

Figure 4: Pooled estimates of blood loss (mL) comparing laparoscopy to laparotomy $\mathrm{Cl}$ confidence interval, $\mathrm{df}$ degrees of freedom

\section{Postoperative morbidity}

\section{Anastomotic leakage}

The data concerning anastomotic leakage were reported in all trials with no significant difference between the two groups. Odds ratio $1.14[0.77,1.68]$ CI $95 \%(\mathrm{p}=0.52)$. (Figure 5).

\section{First bowel movement}

First bowel movement was reported in all trials. Results were reported in median and range in : AlaCart trial [10,11] ,COREAN trial [15,16], ACOSOG Z6051 trial [8,9] and $\mathrm{Ng}$ 's trial[17]. The analysis showed that the first bowel movement was faster in the laparoscopy group (mean difference -0.53 days $[-0.65,-0.41]$ CI $95 \% \mathrm{p}<0.00001$ ) (Figure 6).

\section{Hospital stay}

Length of hospital stay (days) was reported in five trials. For missing data, in the COLOR II trial [13, 14], it affected $15 / 699$ in the laparoscopy group and $8 / 345$ in the laparotomy group. Results were presented in median and range in AlaCart trial $[10,11]$ COREAN trial $[15,16]$ and $\mathrm{Ng}$ 's trial[17]. Findings showed that hospital stay was shorter in the laparoscopy group, but not statistically significant: Mean difference -0.29 days [-0.72, 0.13] CI 95\% $(\mathrm{p}=0.18) \quad($ Figure 7$)$. 
ISSN: 2351-8200

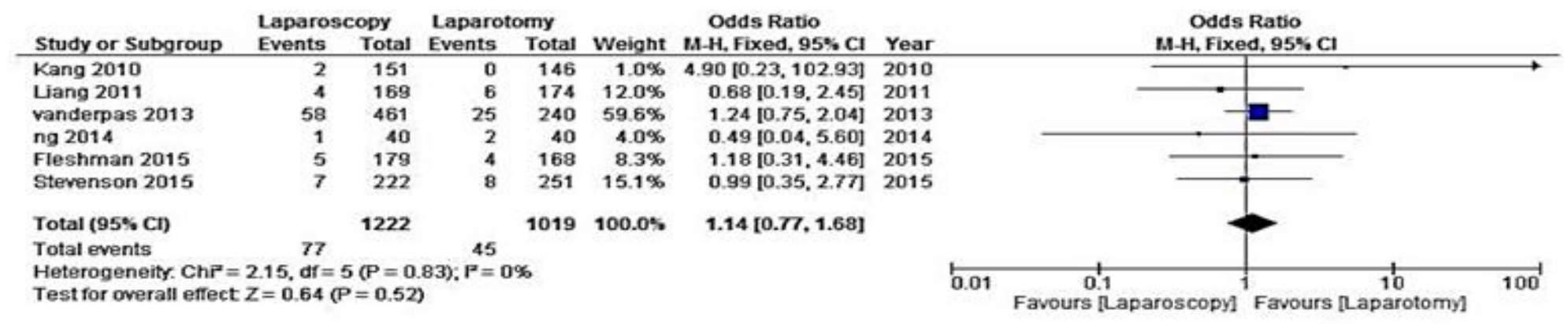

Figure 5 : Pooled estimates of anastomotic leakage comparing laparoscopy to laparotomy. CI confidence interval, df degrees of freedom

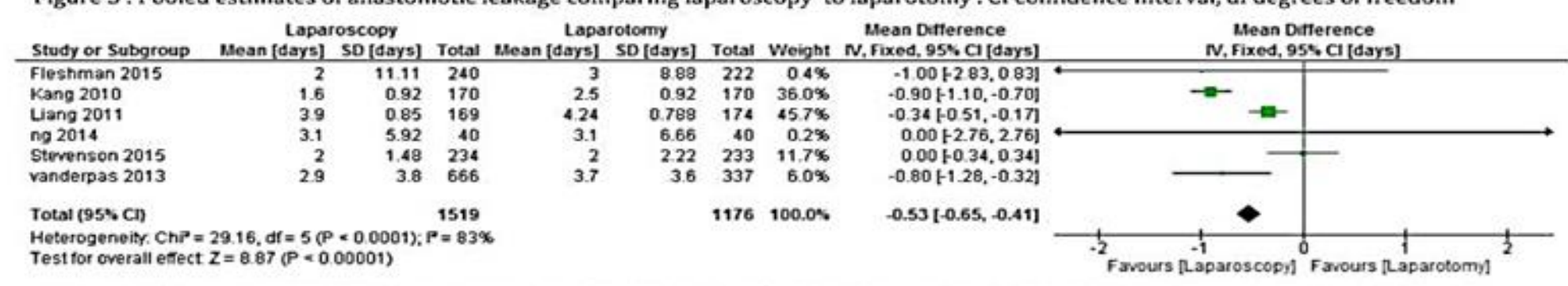

Figure 6: Pooled estimates of first bowel movement comparing laparoscopy to laparotomy. Cl confidence interval, df degrees of freedom

\begin{tabular}{|c|c|c|c|c|c|c|c|c|c|c|c|}
\hline \multirow[b]{2}{*}{ Study or Subgroup } & \multicolumn{3}{|c|}{ Laparoscopy } & \multicolumn{3}{|c|}{ laparotomy } & \multirow{2}{*}{\multicolumn{2}{|c|}{$\begin{array}{ll} & \text { Mean Difference } \\
\text { Weight } & \text { N. Fixed, } 95 \% \text { Cl } \\
\end{array}$}} & \multirow{2}{*}{\multicolumn{3}{|c|}{$\begin{array}{l}\text { Mean Difference } \\
\text { N, Fixed, } 95 \% \text { CI }\end{array}$}} \\
\hline & Mean & SD & Total & Mean & SD & Total & & & & & \\
\hline Fleshman 2015 & 7.3 & 5.4 & 240 & 7 & 3.4 & 222 & $27.2 \%$ & $0.30[-0.52,1.12]$ & & & \\
\hline Kang 2010 & 8 & 3.7 & 170 & 9 & 2.96 & 170 & $35.7 \%$ & $-1.00[-1.71,-0.29]$ & $a$ & & \\
\hline ng 2014 & 10.5 & 22.22 & 40 & 15 & 119.25 & 40 & $0.0 \%$ & $-4.50[-42.09,33.09]$ & $\leftarrow$ & & \\
\hline Stevenson 2015 & 8 & 4.44 & 238 & 8 & 4.44 & 235 & $28.3 \%$ & $0.00-0.80,0.80]$ & & & \\
\hline vanderpas 2013 & 11.9 & 11.8 & 684 & 12.1 & 10.6 & 337 & $8.8 \%$ & $-0.20[-1.64 .1 .24]$ & & & \\
\hline Total $(95 \% \mathrm{CI})$ & & & 1372 & & & 1004 & $100.0 \%$ & $-0.29[-0.72,0.13]$ & & & \\
\hline $\begin{array}{l}\text { Heterogeneity: Chr" } \\
\text { Test for overall effect }\end{array}$ & $\begin{array}{l}3.39, \mathrm{df} \\
Z=1.35\end{array}$ & $\begin{array}{l}=4 P= \\
(P=0 .\end{array}$ & $\begin{array}{l}0.177 \text {; } \\
\text { 8) }\end{array}$ & $=37 \%$ & & & & & Favours [Laparoscopy] & Favours & ${ }_{\text {[Laparotomy] }}^{1}$ \\
\hline
\end{tabular}

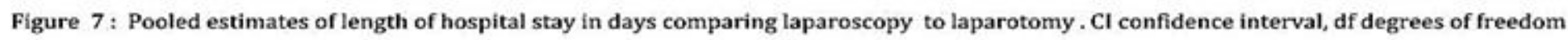

\section{Mortality}

All trials studied 30-days mortality after surgery. Out of a total of 2742 patients, 1556 were in the laparoscopy group and 1186 patients in the laparotomy group .The analysis showed less mortality in the laparoscopy group but statistically not significant (Odds ratio 0.67[0.28, 1.61] CI $95 \% \cdot \mathrm{p}=0.37)($ Figure 8)

\section{Reoperation}

Three trials reported data on reoperation, and findings showed no statistically significant difference between the two groups (Odds ratio 1.18 [0.84, 1.64] CI 95\%. p = 0.34) (Figure 9) 


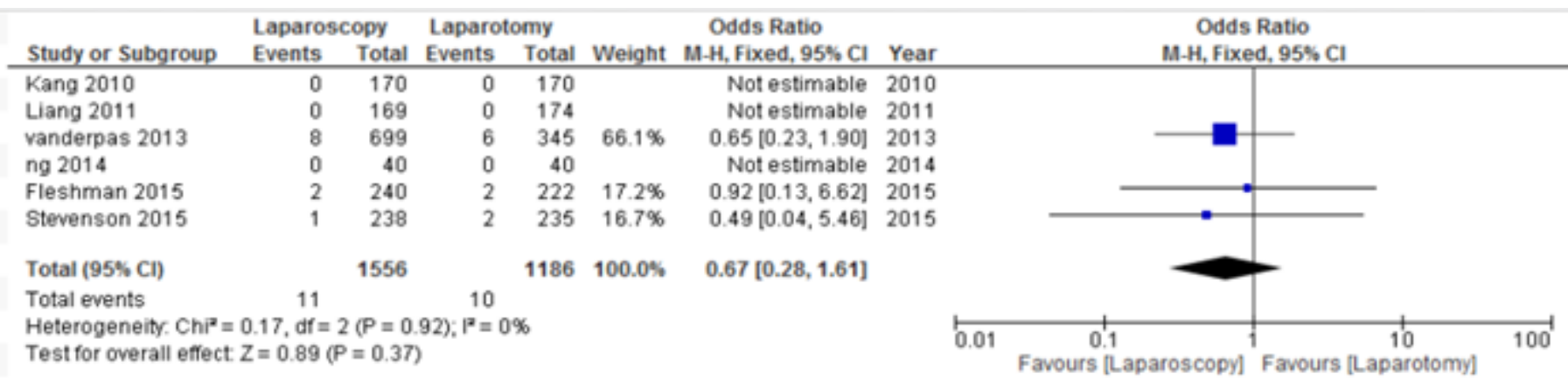

Figure 8 : Pooled estimates of 30-days mortality after surgery comparing laparoscopy to laparotomy. $\mathrm{Cl}$ confidence interval, df degrees of freedom

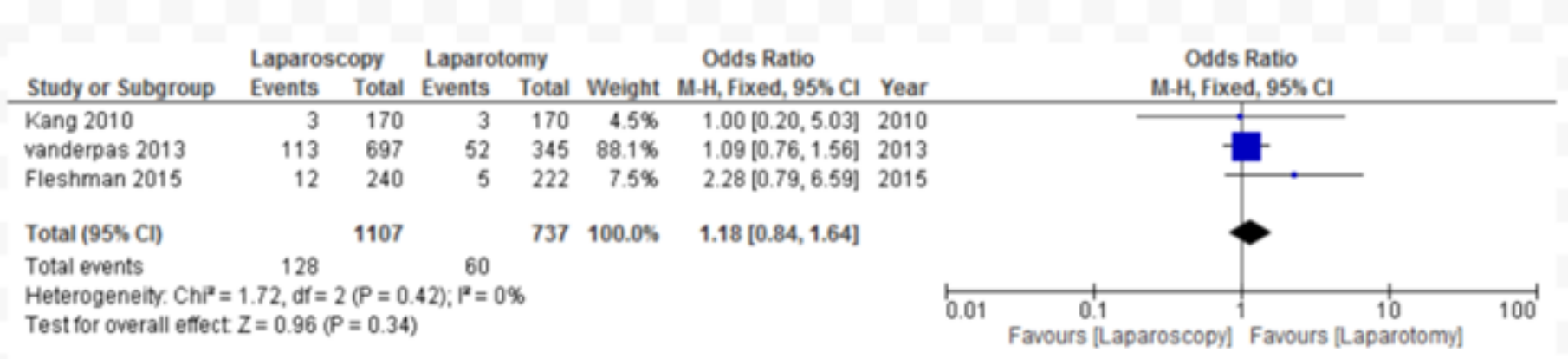

Figure 9: Pooled estimates of reoperation comparing laparoscopy to laparotomy. $\mathrm{Cl}$ confidence interval, df degrees of freedom

of positive CRMs between the two groups: Odds ratio 1.07 $[0.77,1.47]$ CI 95\% $(p=0.70)$ (Figure 11)

\section{Quality of resected specimen}

\section{Harvested lymph nodes}

The number of harvested lymph nodes was reported in 5 trials, a total of 1339 patients. There was missing data was $16 / 699(2 \%)$ in the laparoscopy group and $4 / 345(1 \%)$ in the laparotomy group in the COLOR II trial $[13,14]$. COREAN trial $[15,16]$ and COLOR II trial $[13,14]$ reported results using median and range. All the studies were in favour of the laparoscopy, except Ng's trial [17]. The number of harvested lymph nodes was statistically higher in the laparoscopy group: Mean difference -0.46 [-0.83, -0.09] CI 95\% ( $\quad=0.01)$ (Figure 10).

\section{CRM Operative duration}

Positive circumferential resection margins $(\mathrm{CRM}) \leq 1 \mathrm{~mm}$ was reported in five trials. Missing data concerned COLOR II trial $[13,14]$ with $78 / 666(12 \%)$ in the laparoscopy group and $26 / 326(8 \%)$ in the laparotomy group. In the AlaCart trial $[10,11]$, data was provided for $211 / 238$ patients in the laparoscopy group and 201/235 patients in the laparotomy group. On the basis of 1249 patients in the laparoscopy group and 933 patients in the laparotomy group, no statistically significant differences were found in the number

\section{Quality of mesorectum}

Data on the completeness of mesorectal excision were reported in five trials, including 2337 patients, 1348 in the laparoscopy group and 989 in the laparotomy group. Concerning missing data, in the COLOR II trial [13, 14], it was 33/699 in the laparoscopy group and 14/345 in the laparotomy group, and in the AlaCart trial [10,11],, it was $27 / 238$ in the laparoscopy group and $34 / 235$ in the laparotomy group. In three trials, the classification proposed by Nagtegaal et al. [20] was used, describing the excision of the mesorectum as complete, nearly complete or incomplete. In the COLOR II trial [13, 14], the excision of the mesorectum was qualified as complete, partially complete or incomplete. In Ng's trial [17], only complete mesorectal excision was reported. In order to do a metaanalysis we considered partially complete mesorectal excision as complete, in the COLOR II trial [13, 14]. We also considered nearly complete as complete in opposition to incomplete, according to Nagtegaal's paper [20]. Thus, we compared incomplete mesorectal excision in the five trials, out of 1348 patients in the laparoscopy group and 989 patients in the laparotomy group. Findings showed that there were no significant differences among the studies: Odds ratio $1.30[0.85,1.99]$ CI 95\% $(\mathrm{p}=0.23)$ (Figure 12). 
Journal of Medical and Surgical Research JMSR 2021 Vol. VIII, n 1: 948- 965

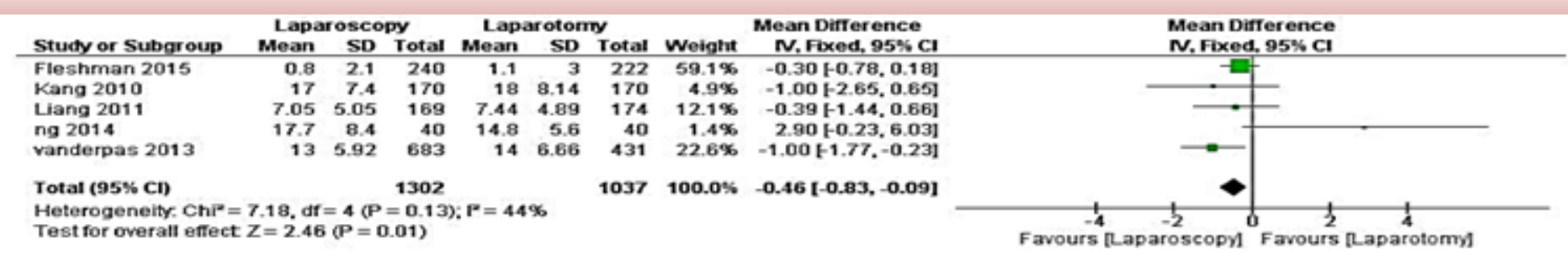

Test for overall effect $Z=2.46(P=0.01$

Figure 10:Pooled estimates of harvested lymph nodes comparing laparoscopy to laparotomy. Cl confidence interval, df degrees of freedom

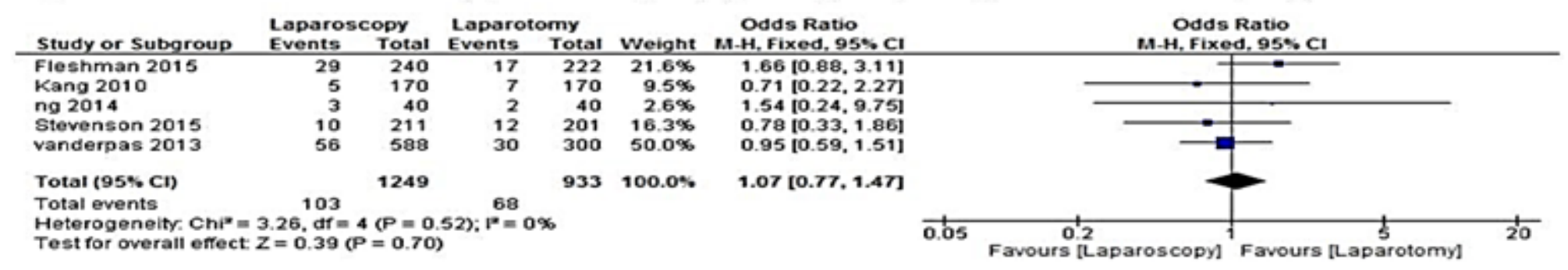

Figure 11: Pooled estimates of Positive CRM comparing laparoscopy to laparotomy. Cl confidence interval, df degrees of freedom

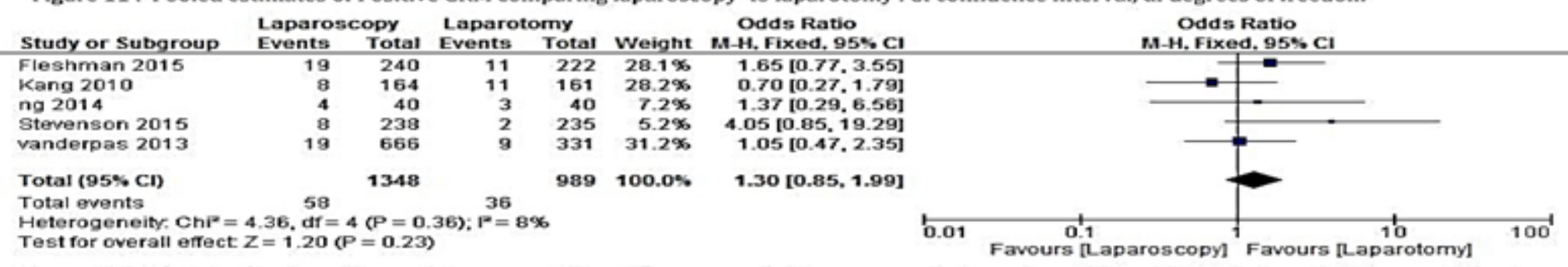

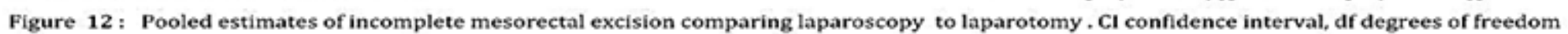

\section{LONG TERM OUTCOMES}

Data about long term outcomes were not reported homogeneously between studies. Therefore, we were not able to perform a meta-analysis.

\section{Recurrences}

In the AlaCart trial [11], loco-regional recurrence rates at 2 years were $5.4 \%$ in the laparoscopy group and $3.1 \%$ in the laparotomy group [difference, 2.3\%; 95\% confidence interval (CI), $1.5 \%$ to $6.1 \%$; hazard ratio (HR) $1.7 ; 95 \% \mathrm{CI}$, 0.74-3.9]. Four trials reported the locoregional recurrence rate at 3 years. In the COLOR II trial[14], the locoregional recurrence rate at 3 years was $5.0 \%$ in the two groups (difference, 0 percentage points; $90 \%$ confidence interval[CI], -2.6 to 2.6).In the Corean trial[16], the locoregional recurrence rate at 3 years was $2 \cdot 6 \%(1 \cdot 0$ to $6 \cdot 7)$ in the laparoscopy group and $4 \cdot 9 \%(2 \cdot 5$ to $9 \cdot 6)$ in the laparotomy group, difference $2 \cdot 3 \%(-1 \cdot 8$ to $6 \cdot 4)$.The ACOSOG Z6051 trial[8] had studied local, regional and distant recurrence at $3,6,9,12,18$ and 24 months. Locoregional recurrence rates at 2 years were $2.1 \%$ in the laparoscopy group and $1.8 \%$ in the laparotomy $(\mathrm{P}=0.86)$. Distant metastasis was similar between the groups (14.6\% in the laparoscopy group; $16.7 \%$ in the laparotomy group).
In Ng's trial [17], loco-regional recurrence rates at 5 years were not different between the two groups: $2.8 \%$ in the laparoscopy group and $8.9 \%$ in the laparotomy group $(\mathrm{p}=0.187)$.

To conclude, no difference was found between the two groups for locoregional recurrences.

\section{DISEASE-FREE SURVIVAL}

Two trials presented the disease free survival DFS at 3 years .The COLOR II trial [14] survival rates were $74.8 \%$ in the laparoscopy group and $70.8 \%$ in the laparotomy group (difference, 4.0 percentage points; $95 \% \mathrm{CI},-1.9$ to 9.9 ). The Corean trial [16] found a 3 years disease-free survival rate at $72 \cdot 5 \%(95 \% \mathrm{CI} 65 \cdot 0-78 \cdot 6)$ for the laparotomy group and $79 \cdot 2 \%(72 \cdot 3-84 \cdot 6)$ for the laparoscopy group. Two trials presented the disease free survival at 2 years. For the AlaCart trial [11], the disease free survival at 2 years was $80 \%$ in the laparoscopy group and $82 \%$ in the laparotomy group, a difference of $2.0 \%(95 \% \mathrm{CI}, 9.3 \%$ to $5.4 \%)$. For the ACOSOG Z6051 trial [8], the 2-years DFS was 79.5\% (95\% confidence interval [CI]74.4-84.9) for the laparoscopy group and $83.2 \%$ (95\% CI 78.3-88.3) for the laparotomy group. $\mathrm{Ng}$ 's trial [17] concluded that probabilities of being disease-free at 5 years were $83.3 \%$ for the laparoscopy group and $74.5 \%$ for the laparotomy group $(\mathrm{P}=0.114)$. 
ISSN: 2351-8200

In summary, disease-free survival was the same in the laparoscopy group and in the laparotomy group. In summary, disease-free survival was the same in the laparoscopy group and in the laparotomy group.

\section{OVERALL SURVIVAL}

Three trials reported overall survival at 3 years. In the COLOR II trial [14], Overall survival rates at 3 years were $86.7 \%$ in the laparoscopy group and $83.6 \%$ in the laparotomy group (difference, 3.1 percentage points; $95 \%$ CI, -1.6 to 7.8 ).

In the Corean trial [16], the overall survival rates at 3 years were $90 \cdot 4 \%(84 \cdot 9$ to $94 \cdot 0)$ in the laparotomy group and $91 \cdot 7 \%(86 \cdot 3$ to $95 \cdot 0)$ in the laparoscopy group. In Liang's trial [18], overall survival rates at 3 years were $76.0 \%$ in the laparoscopy group and $82.8 \%$ in the laparotomy group $(\mathrm{p}=0.462)$.

Two trials studied overall survival at 2 years. In Liang's trial [18], 2-year survival was $82.6 \%$ in the laparoscopy group and $91.2 \%$ in the laparotomy group $(\mathrm{p}=0.462)$.

In AlaCart trial [11], overall survival rates at 2 years were $94 \%$ in the laparoscopy group and $93 \%$ in the laparotomy group (difference $0.9 \%$; $95 \% \mathrm{CI}, 3.6 \%$ to $5.4 \%$ ).
Ng's trial [17] reported overall survival at 5 and 8 years , and were 85.9 and $82 \%$, respectively for the laparoscopy group, and 91.3 and $72.7 \%$, respectively for the laparotomy group $(\mathrm{p}=0.912)$.

In summary, no difference was found concerning the overall survival between laparoscopy and laparotomy.

\section{DISCUSSION}

Our meta-analysis was in favour of laparoscopy in a significant way for blood loss, first bowel movement and the number of harvested lymph nodes. However, it was nonsignificantly in favour of laparoscopy for 30-days mortality after surgery and length of hospital stay. It was significantly in favour of laparotomy concerning operation duration.

No significant differences were found concerning anastomotic leakage, reoperation within 30 days, number of positive CRMs and completeness of mesorectum excision. Also no difference was found in recurrence, disease-free survival and overall survival between laparoscopy group and laparotomy group. We conducted the search in PubMed for all meta-analysis published and found 38 papers. Postscreening, we retained 24 meta-analyses to discuss shortterm outcomes. The results of the meta-analyses were classified in tables from the most recent to the oldest (Tables III, IV, V). To discuss long term outcomes, we have retained only recent meta-analysis, published in 2018 and 2017. 


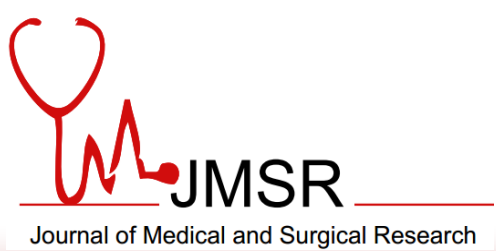

Table IV: Table summarizing meta-analysis‘s short term outcomes (from 2013 to 2017)

\begin{tabular}{|c|c|c|c|c|c|c|c|c|c|c|}
\hline & $\begin{array}{l}\text { Operative } \\
\text { duration }\end{array}$ & $\begin{array}{l}\text { Blood } \\
\text { loss }\end{array}$ & $\begin{array}{c}\text { Hospital } \\
\text { stay }\end{array}$ & $\begin{array}{c}\text { Anastomotic } \\
\text { leakage }\end{array}$ & $\begin{array}{c}\text { First } \\
\text { bowel } \\
\text { movement }\end{array}$ & $\begin{array}{l}\text { Reoperation } \\
\text { within } \\
30 \text { days }\end{array}$ & $\begin{array}{c}\text { 30-days } \\
\text { mortality } \\
\text { after } \\
\text { surgery }\end{array}$ & $\begin{array}{l}\text { Number } \\
\text { of harvested } \\
\text { lymph } \\
\text { nodes }\end{array}$ & $\begin{array}{c}\text { Positive } \\
\text { circumferential } \\
\text { resection margins }\end{array}$ & $\begin{array}{c}\text { Completeness } \\
\text { of } \\
\text { mesorectal } \\
\text { excision }\end{array}$ \\
\hline $\begin{array}{l}\text { (Martine } \\
\text { z- Perez et } \\
\text { al 2017) })^{34}\end{array}$ & B & A & A & C & A & C & C & C & C & B \\
\hline $\begin{array}{r}\quad(\text { Creavin } \\
\text { et al 2017) }\end{array}$ & - & - & - & - & - & - & - & C & C & C \\
\hline $\begin{array}{c}\text { (Zheng } \\
\text { et al 2017) }\end{array}$ & B & A & A & - & A & - & A & C & A & C \\
\hline $\begin{array}{l}\text { (Jiang et } \\
\text { al 2015) }\end{array}$ & B & A & A & C & A & - & C & C & C & - \\
\hline $\begin{array}{r}\text { (Arezzo } \\
\text { et al 2015) }\end{array}$ & B & - & A & C & A & - & - & C & C & - \\
\hline $\begin{array}{r}\text { (Hua et } \\
\text { al 2014) }\end{array}$ & - & - & - & C & - & - & - & - & - & - \\
\hline $\begin{array}{c}\quad \text { (Zhang } \\
\text { et al 2014) }\end{array}$ & B & A & A & $\mathrm{C}$ & A & $\mathrm{C}$ & C & C & $\mathrm{C}$ & C \\
\hline $\begin{array}{r}\quad \text { (Arezzo } \\
\text { et al 2013) }\end{array}$ & A & A & A & $\mathrm{C}$ & A & A & A & - & - & - \\
\hline $\begin{array}{r}\text { (Qu et } \\
\text { al } 2013)^{41}\end{array}$ & - & A & A & $\mathrm{C}$ & A & - & - & C & - & - \\
\hline
\end{tabular}




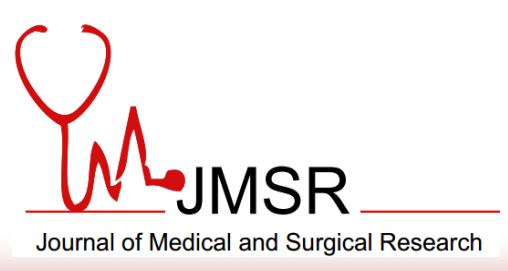

Table V: Table summarizing meta-analysis‘s short term outcomes (from 2006 to 2012).

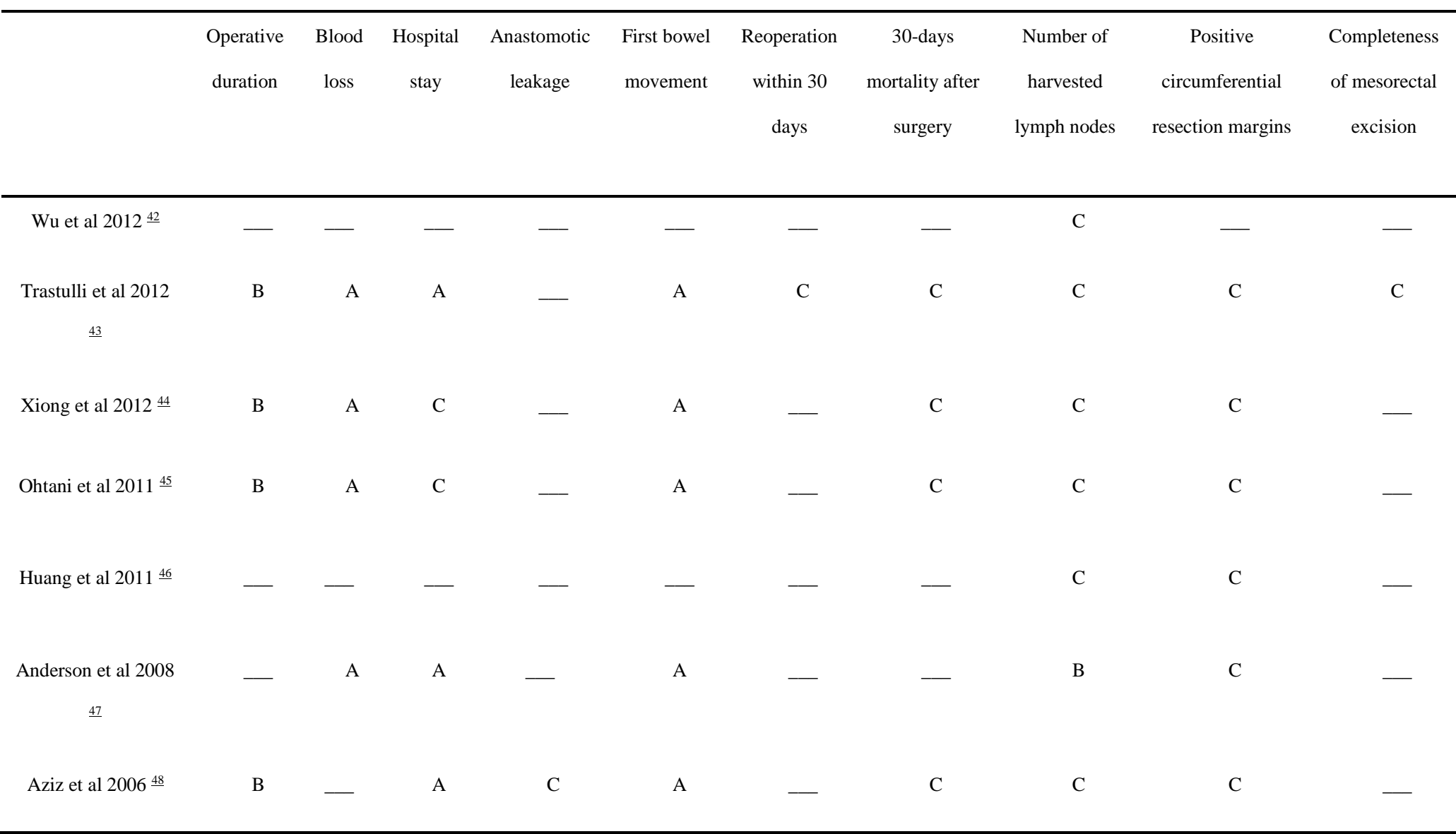

$\mathrm{A}=$ Significantly in favour of laparoscopy $; \mathrm{B}=$ Significantly in favour of laparotomy $; \mathrm{C}=$ No significant difference found between laparoscopy and laparotomy 


\section{SHORT TERM OUTCOMES}

\section{Per operative outcomes}

As expected, the operative duration was shorter in the laparotomy group in our meta-analysis. The same result was reported in the CLASICC trial [5] and in a systematic review and meta-analysis published in 2012 by A.Arezzo [23].

.M. Pedziwiatr's paper [24], which is the most recent meta-analysis regarding this topic, didn't cover this outcome, probably judging that literature had already proved it. Concerning blood loss, the findings showed that it was statistically lower in the laparoscopy group. Thereby, it corroborates literature as in a Arezzo et al. meta-analysis [23]

The CLASICC trial [5] had studied the blood transfusion requirement, which indirectly reflects blood loss. No difference was found between the laparoscopy group and the laparotomy group in transfusion requirement, which allows us to conclude that blood loss was almost similar for the two techniques .

\section{Postoperative morbidity}

As expected, hospital stay was shorter in the laparoscopy group in our meta-analysis, just like in Arezzo et al. meta-analysis[23]. As in the CLASICC trial [5] in which it was 2 days shorter for the laparoscopy group.

For anastomotic leakage, no difference was found in our meta-analysis between the two groups, just like in the CLASICC trial [5] and in A.Arezzo's meta-analysis [23] First bowel movement was faster in the laparoscopy group according to our meta-analysis and to A.Arezzo's meta-analysis[23], whereas the CLASICC trial[5] found no difference between the two groups.

Concerning reoperation, findings showed no difference statistically significant. In A.Arezzo's meta-analysis[23], surgical complications within 30 days were reported, and were significantly in favour of the laparoscopy group. The CLASICC trial [5] didn't present data concerning this item .

Our meta-analysis, just like A.Arezzo's metaanalysis[23] showed a lower 30-days mortality after surgery in the laparoscopy group but statistically not significant. The CLASICC trial [5]didn't present data concerning this item .

\section{Quality of resected specimen}

This systematic review and meta-analysis concluded that the number of harvested lymph nodes was statistically higher in the laparoscopy group. According to the literature, there was no difference in the number of harvested lymph nodes between the laparoscopic and the laparotomy group, as shown in the CLASICC trial [5] and in M.Pedziwiatr 's meta-analysis [24] published in 2017, which found that lymph node yield depended on several factors like the tumour itself, the patient, neoadjuvant radiochemotherapy, pathologic assessment [25] and, of course , the surgeon [26]. That final point can explain the difference of the findings between literature and this meta-analysis. By selecting only trials done after 2010, we minimized the bias related to the learning curve of the laparoscopy, so the oncological results were more representative.

Concerning positive circumferential resection margins $(\mathrm{CRM}) \leq 1 \mathrm{~mm}$, no difference statistically significant was found between the two groups. Positive circumferential resection margins represented $8.24 \%$ in the laparoscopy group comparatively to $7.28 \%$ in the laparotomy group, despite missing data representing $8.4 \%$ in the laparoscopy group and $6.4 \%$ in the laparotomy group. On the same side, a recent meta-analysis made by $\mathbf{M}$. Pedziwiatr [24] concluded to the same finding and suggested that the differences in CRM involvement between studies were related to the quality of surgery or (less probably) to the differences in pathologic assessment (there were no use of neoadjuvant therapy or pre-operative differences in $\mathrm{T}$ stage between groups). On the other side, the early results from CLASICC trial [5] showed higher but non-significant rates of circumferential resection margin (CRM) involvement following laparoscopic anterior resection. Nevertheless, at 3-year follow-up the difference in CRM positivity had not translated into a difference in local recurrence rates between laparoscopy and laparotomy.

In our meta-analysis, the completeness of mesorectal excision was similar regardless to the technique used. This result joins the M. Pedziwiatr's meta-analysis [24] and which raised the question of the difference of overall survival between complete and nearly complete mesorectal excisions. Through this question, we criticize the real impact of a resection considered almost the same (Nagtegaal et al[20]) on survival, and indirectly we evaluate the weight of this parameter.

Ten years ago, the CLASICC trial [5] showed that total mesorectal excision was in favour of the laparoscopy and justifying this finding by the fact that the procedure is technically easier in laparoscopic surgery than in laparotomy. This made us wonder what has changed over the years, so that the completeness of mesorectal excision became independent of the surgery technique. 


\section{LONG-TERM OUTCOMES}

We compared long term outcomes of our meta-analysis with the most recent meta-analysis , published in 2018 and 2017 . On ten papers, only three analysed locoregionnal recurrences, DFS and overall survival .

\section{Recurrences}

The results have been reported during different periods in the selected trials.

One trial reported locoregional recurrence at 3, 6, 9, 12, 18 and 24 months, another one at 2 years, another trial at 5 years and four others at 3 years.

In our systematic review, no difference was found between the two groups concerning locoregional recurrences. Even in literature, no difference was found between the two groups concerning locoregional recurrence at 5 years according to Nienhüser's metaanalysis[29] and Pedziwiatr's meta-analysis [24]

\section{Disease-free survival}

Two trials reported DFS at 2 years, two others at 3 years and one in 5 years. In our meta-analysis, no difference was found in disease-free survival between laparoscopy and laparotomy.This result is in line with literature. In Lin's meta-analysis [31] and In Nienhüser's metaanalysis[29] no difference was found in 5 years disease-free survival. In M.Pedziwiatr's meta-analysis [24] disease-free survival rates were reported at 3 and 5 years and no difference was found between the two groups $(\mathrm{p}=0.26$ and $\mathrm{p}=0.71$ respectively).

\section{Overall survival}

Three trials reported overall survival at 3 years, two at 2 years and one at 5 and 8 years.

In our meta-analysis, no difference was found concerning the overall survival between laparoscopy and laparotomy. This finding corroborates with literature. As in Lin's meta-analysis[31] and in Nienhüser's metaanalysis [29] where no difference was found in overall survival at 5 years between laparoscopy and laparotomy. In M.Pedziwiatr's meta-analysis [24] no difference was found in overall survival at 3 and 5 years between the two groups ( $\mathrm{p}=0.19$ and $\mathrm{p}=0.64$ respectively).

In the 90's the mastery of laparoscopy was defined by the number of hours of practice. Simons Anthony J. M.D[49] proposed that operating 11 to 15 completed laparoscopic colectomies are needed to learn the procedure. On this basis ,the CLASICC trial [5] had selected 32 surgeons. In the meta-analysis previously cited, most trials provided no information on the surgical expertise of the credentialed surgeons.

All the trials of our meta-analysis had strict eligibility criterias for including surgeons, and differed from a trial to another. For example, for the COLOR II trial[14], surgical competency was assessed on the basis of review of recorded images or live observations of laparoscopic TME surgeries. Accreditation was done by center instead of individual surgeons. [5] Concerning AlaCart trial[10,11], the eligibility criteria required more than 100 laparoscopic colon resections and more than 30 laparoscopic rectal dissections that were verified by operation and pathology reports.

Surgeons were required to submit an unedited video of a laparoscopic total mesorectal excision in a male patient. These reports and videos were independently audited by 2 of the study's senior surgeons. [10]

The difficulty of this study lies in the diversity of the follow up period, and makes impossible homogenization of the long term outcomes for comparison purposes. For example AlaCart trial[10,11] , reported 2 years diseasefree survival, while COLOR II[14] reported 3 years disease free-survival and this imposed the creation of subgroups to be able to compare the results.

\section{CONCLUSIONS}

This systematic review with a meta-analysis showed that laparoscopic surgery for rectal cancer had higher number of harvested lymph nodes, an equal postoperative morbidity, survival rate and recurrences compared to laparotomy. Our meta-analysis showed the same short-term outcomes than meta-analysis published after 2010 , except the number of harvested lymph nodes which was higher in the laparoscopy in our study while other studies, published before 2010 reported no difference between the two techniques. Our metaanalysis had shown also the same long term outcomes than the most recent meta-analysis, confirming that no difference was found concerning recurrence, disease-free survival and overall survival between laparoscopy and laparotomy.

To date, despite moving forward toward new miniinvasive techniques such as robotic surgery and transanal total mesorectal excision, and despite several randomized trials and meta-analysis, the role of laparoscopy in rectal cancer resection is still debatable. The results from real life large databases could perhaps better clarify the role of laparoscopy in the treatment of rectal adenocarcinoma. 


\section{CONFLICT OF INTEREST:}

The Author(s) declare(s) that there is no conflict of interest.

\section{FUNDINGS:}

No Fundings to declare.

\section{REFERENCES:}

1. Fleshman, J. et al. Disease-free Survival and Local Recurrence for Laparoscopic Resection Compared With Open Resection of Stage II to III Rectal Cancer: Followup Results of the ACOSOG Z6051 Randomized Controlled Trial. Ann. Surg. 2019; 269 (4): 589-595. doi: 10.1097/SLA.0000000000003002.

2. Fleshman, J. et al. Effect of Laparoscopic-Assisted Resection vs Open Resection of Stage II or III Rectal Cancer on Pathologic Outcomes: The ACOSOG Z6051 Randomized Clinical Trial. JAMA. 2015; 314 (13): 1346-1355. doi: 10.1001/jama.2015.10529.

3. Stevenson, A. R. L. et al. Effect of LaparoscopicAssisted Resection vs Open Resection on Pathological Outcomes in Rectal Cancer: The ALaCaRT Randomized Clinical Trial. JAMA. 2015; 314 (13): 1356-1363. doi: 10.1001/jama.2015.12009.

4. Stevenson, A. R. L. et al. Disease-free Survival and Local Recurrence After Laparoscopic-assisted Resection or Open Resection for Rectal Cancer: The Australasian Laparoscopic Cancer of the Rectum Randomized Clinical Trial. Ann. Surg. 2019; 269 (4): 596-602 . doi: 10.1097/SLA.0000000000003021

5. Kienle, P., Weitz, J., Koch, M. \& Buchler, M. W. Laparoscopic surgery for colorectal cancer. Colorectal Disease. 2006; VIII Suppl 3: 33-36 . doi: 10.1111/j.1463-1318.2006.01069.x.

6. Milsom, J. W. \& Kim, S.-H. Laparoscopic versus Open Surgery for Colorectal Cancer. World Journal of

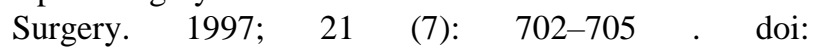
$10.1007 / \mathrm{s} 002689900294$

7. Monson JR et al; Standards Practice Task Force of the American Society of Colon and Rectal Surgeons. Practice parameters for the management of rectal cancer (revised). Dis Colon Rectum. 2013; 56 (5): 535-50. doi: 10.1097/DCR.0b013e31828cb66c.

8. Website: Laparoscopic Proctectomy for Curable Cancer. Position Statement of the American Society of Colon \& Rectal Surgeons (ASCRS) and of the Society of Gastrointestinal and Endoscopic Surgeons (SAGES) www.fascrs.org.

9. Guillou, P. J. et al. Short-term endpoints of conventional versus laparoscopic-assisted surgery in patients with colorectal cancer (MRC CLASICC trial): multicentre, randomised controlled trial. Lancet. 2005; 365 (9472): 1718- 1726 . doi: 10.1016/S01406736(05)66545-2

10. Jayne, D. G. et al. Randomized Trial of Laparoscopic-Assisted Resection of Colorectal Carcinoma: 3-Year Results of the UK MRC CLASICC Trial Group. Journal of Clinical Oncology. 2007; 25 (21): 3061-3068 . doi: 10.1200/JCO.2006.09.7758.

11. Arulampalam et al. MRC CLASICC trial. The Lancet. 2005; 366 (9487): 712. DOI: 10.1016/S01406736(05)67168-1

12. Website. Higgins JPT, Thomas J, Chandler J, Cumpston M, Li T, Page MJ, Welch VA (editors). Cochrane Handbook for Systematic Reviews of Interventions version 6.0 (updated July 2019). Cochrane, 2019. Available from www.training.cochrane.org/handbook.

13. Pas, M. H. van der et al. Laparoscopic versus open surgery for rectal cancer (COLOR II): short-term outcomes of a randomised, phase 3 trial. The Lancet Oncology. 2013; 14 (3): 210-218 . doi: 10.1016/S14702045(13)70016-0.

14. Bonjer, H. J. et al. A randomized trial of laparoscopic versus open surgery for rectal cancer. N. Engl. J. Med. 2015; 372 (14): 1324-1332. doi: 10.1056/NEJMoa1414882.

15. Kang, S.-B. et al. Open versus laparoscopic surgery for mid or low rectal cancer after neoadjuvant chemoradiotherapy (COREAN trial): short-term outcomes of an open-label randomised controlled trial. Lancet Oncol. 2010; 11 (7): 637-645. doi: 10.1016/S1470-2045(10)70131-5.

16. Jeong, S.-Y. et al. Open versus laparoscopic surgery for mid-rectal or low-rectal cancer after neoadjuvant chemoradiotherapy (COREAN trial): survival outcomes of an open-label, non-inferiority, randomised controlled trial. The Lancet Oncology. 2014; 15 (7): 767-74. doi: 10.1016/S1470-2045(14)70205-0.

17. Ng, S. S. M. et al. Laparoscopic-assisted versus open total mesorectal excision with anal sphincter preservation for mid and low rectal cancer: a prospective, randomized trial. Surgical Endoscopy. 2014; 28 (1): 297-306. doi: 10.1007/s00464-013-3187-x. 18. Liang, $X$. et al. Effectiveness and safety of laparoscopic resection versus open surgery in patients with rectal cancer: a randomized, controlled trial from China. J. Laparoendosc. Adv. Surg. Tech. 2011; 21 (5): 381-385. doi: 10.1089/lap.2010.0059.

19. Sterne, J. A. C. et al. RoB 2: a revised tool for assessing risk of bias in randomised trials. BMJ. 2019; 366 : 14898. doi: 10.1136/bmj.14898.

20. Nagtegaal, I. D. et al. Macroscopic evaluation of rectal cancer resection specimen: clinical significance of 
the pathologist in quality control. J. Clin. Oncol. 2002; 20 (7): 1729-1734. doi: 10.1200/JCO.2002.07.010.

21. 7.7.3.5 Medians and interquartile ranges. https://handbook-5-

1.cochrane.org/chapter_7/7_7_3_5_mediansand_interqu artile_ranges.htm.

22. Table 9.4.a: Summary of meta-analysis methods available in RevMan. https://handbook-51.cochrane.org/chapter_9/table_9_4_a_summary_of_met a_analysis_methods_available_in.htm.

23. Arezzo et al. Laparoscopy for rectal cancer reduces short-term mortality and morbidity: results of a systematic review and meta-analysis. Surg. Endosc.2013; 27 (5): 1485-1502 . doi: 10.1007/s00464012-2649-x.

24. Pedziwiatr, M. et al. There is no difference in outcome between laparoscopic and open surgery for rectal cancer: a systematic review and meta-analysis on short- and long-term oncologic outcomes. Tech. Coloproctol. 2017; 21 (8): 595-604. doi: 10.1007/s10151-017-1662-4.

25. Shaw, A. et al. Colorectal surgeons and biomedical scientists improve lymph node harvest in colorectal cancer. Tech. Coloproctol. 2008; 12: 295-298. doi: 10.1007/s10151-008-0438-2.

26. Mekenkamp, L. J. M. et al. Lymph node retrieval in rectal cancer is dependent on many factors--the role of the tumor, the patient, the surgeon, the radiotherapist, and the pathologist. Am. J. Surg. Pathol. 2009; 33 (10): 1547-1553 . doi: 10.1097/PAS.0b013e3181b2e01f.

27. Acuna, S. A. et al. Laparoscopic Versus Open Resection for Rectal Cancer: A Noninferiority Metaanalysis of Quality of Surgical Resection Outcomes. Ann. Surg. 2019; 269 (5): 849-855 . doi: 10.1097/SLA.0000000000003072.

28. Lu, Y. et al. Comparison Between Laparoscopic and Open Resection Following Neoadjuvant Chemoradiotherapy for Mid-Low Rectal Cancer Patients: A Meta-Analysis. J. Laparoendosc. Adv. Surg. Tech. 2019; 29 (3), 316-322. doi: 10.1089/lap.2018.0409.

29. Nienhüser, $H$. et al. Short- and Long-Term Oncological Outcome After Rectal Cancer Surgery: a Systematic Review and Meta-Analysis Comparing Open Versus Laparoscopic Rectal Cancer Surgery. J. Gastrointest. Surg. 2018; 22 (8): 1418-1433. doi: 10.1007/s11605-018-3738-5.

30. Memon et al. Meta-analysis of histopathological outcomes of laparoscopic assisted rectal resection (LARR) vs open rectal resection (ORR) for carcinoma. Am. J. Surg. 2018; 216 (5): 1004-1015. doi: 10.1016/j.amjsurg.2018.06.012.

31. Lin, Z. et al. Short- and long-term outcomes of laparoscopic versus open surgery for rectal cancer: A systematic review and meta-analysis of randomized controlled trials. Medicine. 2018; 97 (50): e13704. doi: 10.1097/MD.0000000000013704.

32. Milone, M. et al. Surgical resection for rectal cancer. Is laparoscopic surgery as successful as open approach? A systematic review with meta-analysis. PLoS One. 2018 ; 13 (10): e0204887. doi: 10.1371/journal.pone.0204887.

33. Martínez-Pérez et al. Pathologic Outcomes of Laparoscopic vs Open Mesorectal Excision for Rectal Cancer: A Systematic Review and Meta-analysis. JAMA Surg. 2017; 152 (4): e165665. doi: 10.1001/jamasurg.2016.5665.

34. Martínez-Pérez et al. N. Short-term clinical outcomes of laparoscopic vs open rectal excision for rectal cancer: A systematic review and meta-analysis. World J. Gastroenterol. 2017; 23 (44): 7906-7916. doi: 10.3748/wjg.v23.i44.7906.

35. Creavin et al. Meta-analysis of the impact of surgical approach on the grade of mesorectal excision in rectal cancer. Br. J. Surg. 2017; 104 (12): 1609-1619. doi: 10.1002/bjs. 10664 .

36. Zheng, J. et al. The comprehensive therapeutic effects of rectal surgery are better in laparoscopy: a systematic review and meta-analysis. Oncotarget. 2017; 8 (8): 12717-12729 . doi: 10.18632/oncotarget.14215.

37. Jiang, J.-B. et al. Short-term and Long-term Outcomes Regarding Laparoscopic Versus Open Surgery for Low Rectal Cancer: A Systematic Review and Meta-Analysis. Surg. Laparosc. Endosc. Percutan. Tech. 2015; $25 \quad$ (4) : 286-296. doi: 10.1097/SLE.0000000000000178.

38. Arezzo, A. et al. Laparoscopy for rectal cancer is oncologically adequate: a systematic review and metaanalysis of the literature. Surg. Endosc. 2015; 29 (2): 334-348. doi: 10.1007/s00464-014-3686-4.

39. Hua, L. et al. Is the incidence of postoperative anastomotic leakage different between laparoscopic and open total mesorectal excision in patients with rectal cancer? A meta-analysis based on randomized controlled trials and controlled clinical trials. J. Cancer Res. Ther. 2014; 10 Suppl: 272-275. doi: 10.4103/09731482.151491.

40. Zhang, F.-W. et al. Laparoscopic Versus Open Surgery for Rectal Cancer: A Systematic Review and Meta-analysis of Randomized Controlled Trials. Asian Pac. J. Cancer Prev. 2014; 15 (22) : 9985- 9996. doi: 10.7314/apjcp.2014.15.22.9985.

41. Qu C. et al. [Meta-analysis of laparoscopic versus open total mesorectal excision for middle and low rectal cancer]. Zhonghua Wei Chang Wai Ke Za Zhi. 2013; 16 (8): 748- 752. PMID: 23980046

42. Wu et al. Lymph node harvested in laparoscopic versus open colorectal cancer approaches: a meta- 
analysis. Surg. Laparosc. Endosc. Percutan. Tech. 2012; 22 (1) : 5- 11. doi: 10.1097/SLE.0b013e3182432b49.

43. Trastulli, S. et al. Laparoscopic vs open resection for rectal cancer: a meta-analysis of randomized clinical trials. Colorectal Dis. 2012; 14 (6): e277-96. doi: 10.1111/j.1463-1318.2012.02985.x.

44. Xiong, B., Ma, L. \& Zhang, C. Laparoscopic versus open total mesorectal excision for middle and low rectal cancer: a meta-analysis of results of randomized controlled trials. J. Laparoendosc. Adv. Surg. Tech. 2012; 22 (7) : 674-684. doi: 10.1089/lap.2012.0143.

45. Ohtani, H. et al. A meta-analysis of the short- and long-term results of randomized controlled trials that compared laparoscopy-assisted and conventional open surgery for rectal cancer. J. Gastrointest. Surg. 2011; 15 : 1375-1385 . doi: 10.1007/s11605-011-1547-1.

46. Huang, M.-J. et al. Laparoscopic-assisted versus open surgery for rectal cancer: a meta-analysis of randomized controlled trials on oncologic adequacy of resection and long-term oncologic outcomes. Int. J. Colorectal Dis. 2011; 26 (4): 415-421. doi: 10.1007/s00384-010-1091-6.

47. Anderson, C., Uman, G. \& Pigazzi, A. Oncologic outcomes of laparoscopic surgery for rectal cancer: a systematic review and meta-analysis of the literature. Eur. J. Surg. Oncol. 2008; 34 (10): 1135-1142. doi: 10.1016/j.ejso.2007.11.015.

48. Aziz, O. et al. Laparoscopic versus open surgery for rectal cancer: a meta-analysis. Ann. Surg. Oncol. 2006; 13 (3): 413-424. DOI: 10.1245/ASO.2006.05.045

49. Simons, A. J. et al. Laparoscopic-assisted colectomy learning curve. Dis. Colon Rectum. 1995; 38 (6): 600603. doi: 10.1007/BF02054118. 